\title{
Future-proofing educational guidance
}

\author{
Nairn Wilson, Professor of Dentistry \\ King's College London Dental Institute
}

The BDJ Upfront section includes editorials, letters, news, book reviews and interviews. Please direct your correspondence to the News Editor,

Kate Quinlan at BDJNews@nature.com. Press releases or articles may be edited, and should include a colour photograph if possible.

$\mathrm{D}$ entistry is undergoing unprecedented and increasing change. If it is to realise its future potential, it must be integrated into general healthcare provision, with game-changing, suitably resourced innovations in interprofessional working, if for no other reason than to address the established association between oral and systemic health. ${ }^{1}$ Beyond dentists becoming as much oral physicians as dental surgeons, ${ }^{2}$ next generation dental graduates will need new skills, attitudes and behaviours. As such the General Dental Council 's (GDC) Preparing for practice 3 could be considered to lack future proofing.

Notwithstanding the absence of learning outcomes in interprofessional healthcare (a failing of all UK educational guidance), 'Preparing for practice' makes no reference to, for example, risk assessment and associated behavioural intervention methodologies to promote patient engagement in healthy living and self care. Further omissions include the IT skills required to derive maximum benefit from the evolving era of digital dentistry and minimal intervention aesthetics, including anti-ageing dentistry. Additional suggested subject areas include transcultural healthcare, non-communicable disease screening, oral healthcare in extreme old age, oral and dental aspects of mental illness, and participation in 'big-data' and related practice-based research.

Could a substantial quantum of new learning be shoehorned into an already over-crowded dental curricula? No, so what are the options, excluding the hugely costly, and unrealistic option of extending the length of undergraduate studies? Should consideration be given to developing a medical model whereby 'safe beginner' graduates complete foundation training and then enter work-based training to become fully trained practitioners? Based on training costs in medicine, this would require substantial new recurrent funding, which is unlikely in the present economic climate. Or, as suggested by Fejerskov and Baelum, ${ }^{4} \mathrm{a}$ more affordable option is to further develop the dental team to create oral healthcare providers - extended duties therapists/ hygienists, and oral clinical specialists, ie dentists capable of delivering an advanced level scope of practice, together with enhanced leadership skills -controversial, but plausible.

Notwithstanding possible up-skilling of the dental team, the extent of the immediate need for new multidisciplinary education, indicates that 'Preparing for practice' needs more than a palliative 'makeover'. Titivation, with expectations that dental schools keep finding efficiency savings is not the answer, nor is a do nothing option', with the consequence that dentistry will get left behind. Whatever the way forward, time is pressing, given the lapse between deciding to change educational guidance and new style suggesting such a programme, it is acknowledged that dental futurology is not an exact science, and that certain innovations, central to new, fit for future purpose guidance, would be based more on predictions than hard evidence. Planning to be prepared is a matter of informed vision: the only good educational guidance is that which pre-empts new circumstances, stimulates engagement and promotes innovation. 'Preparing for practice' lacks such qualities.

The future of dentistry, as an important element of holistic healthcare, is exciting. Regulation, including educational guidance, should encourage such thinking rather than, at present, promote a continuation of traditional, treatment-based dogma, albeit somewhat modernised to take account of recent advances. Wouldn't it be special, let alone a much-

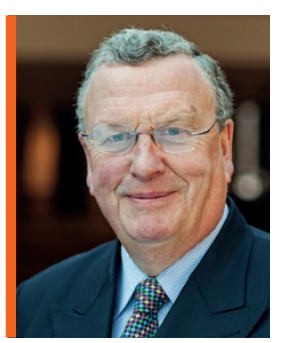

\section{'Wouldn't it be special if UK guidance returned to being the envy of the world?'}

graduates joining the dental workforce; some 8 to 10 years. Dentistry and oral healthcare provision will be very different by $2024 / 26$, but will dental graduates be more or less the same as today, or fit for future purpose thanks to revamped educational guidance?

How should matters be taken forward? Traditionally, the GDC has, in a similar manner to other UK healthcare regulators, led on updating educational guidance for programmes qualifying individuals for registration. If such arrangements prevail, it would be hoped that an approach involving all relevant stakeholders would be adopted. Such an inclusive approach would enable cross-healthcare understanding of the sophistication of dentistry and the importance of oral health to general health. In needed boost for dental education nationally, if UK educational guidance returned to being the envy of the world? This will not happen unless the GDC either delegates modernisation of the guidance to a body such as the Dental Schools Council, or provides the forwarding-thinking leadership that patients and registrants deserve and rightfully expect.

1. Sharma P, Busby M, Chapple L, Matthews R, Chapple I. The relationship between general health and lifestyle factors and oral health outcomes. Br Dent J 2016; 221: 65-69.

2. Mason D. The changing role of the dentist. Br Dent J 1994; 176: 5-9.

3. General Dental Council. Preparing for practice -dental team learning outcomes for registration with the General Dental Council. 201X, London, General Dental Council

4. Fejerskov O, Baelum V. Time for a redo. Dent Absts 2015; 60: 175-176.

DOI: $10.1038 /$ sj.bdj.2016.616 